accordance with National recommendations for children, 2003. Exposure assessment was based on the levels of scalp hair elements and lead in blood. The analysis was done using ICP-MS and AAS methods. Blood lead samples were analysed using the Lead Care instrument. Multiple logistic regression analysis was done with the adjustment for confounders.

Results Concentrations of studied elements were in subtoxic range, average levels were significantly higher in Gus, then in Moscow. In Gus were revealed strong positive associations of BP, especially diastolic, with the tertile rank of blood Lead (in the range $4.4 \mu \mathrm{g} / \mathrm{dl}$ and higher) and hair cerium (in the range $0.7 \mathrm{mkg} / \mathrm{g}$ and higher). $\mathrm{OR}$ for elevated diastolic BP due to Lead was $3.0 ; 95 \%$ CI 0.59 to 15.76 ; $\mathrm{p}<0.186)$; due to Cerium - 3.9; $95 \%$ CI 1.23 to 12.53 ; $\mathrm{p}<0.021)$. In Moscow BP was significantly correlated with the tertile rank of hair nickel (in the range $0.2 \mathrm{mk} / \mathrm{g}$ and higher). OR for elevated systolic $\mathrm{BP}$ due to nickel was 2.5 (95\% CI 1.1 to 5.7, $\mathrm{p}<0.026)$; for diastolic BP - 5,6; 95\% CI 2.2 to 14.6; $\mathrm{p}<0.001)$.

Conclusions The blood Lead, hair Nickel and Cerium levels, even in the low range of concentrations, positively associates with the risk of elevated blood pressure in children.

\section{P2-122 RESPONSE AND PREDICTORS OF RESPONSE, TO PEGYLATED INTERFERON AND RIBAVIRIN FOR CHRONIC HEPATITIS C PATIENTS IN SCOTLAND: ALANINE AMINOTRANSFERASE (ALT) AND GAMMA GLUTAMYL TRANSFERASE (GGT) ARE VALUABLE PRE-TREATMENT MARKERS OF AN SVR IN ROUTINE CLINICAL PRACTICE}

doi:10.1136/jech.2011.142976i.57

\begin{abstract}
1,2 H Innes, ${ }^{* 1,2} \mathrm{~S}$ Hutchinson, ${ }^{3} \mathrm{~S}$ Allen, ${ }^{4} \mathrm{D}$ Bhattacharyya, ${ }^{5} \mathrm{P}$ Bramley, ${ }^{6} \mathrm{~B}$ Carman, ${ }^{7,8} \mathrm{~T}$ Delahooke, ${ }^{9} \mathrm{~J}$ Dillon, ${ }^{1} \mathrm{D}$ Goldberg, ${ }^{10} \mathrm{~N}$ Kennedy, ${ }^{11} \mathrm{P}$ Mills, ${ }^{12} \mathrm{~J}$ Morris, ${ }^{13} \mathrm{~J}$ Morris, ${ }^{12} \mathrm{~A}$ Stanley, ${ }^{1} \mathrm{P}$ Hayes. ${ }^{1}$ Health Protection Scotland, Glasgow, UK; ${ }^{2}$ Department of Mathematics and Statistics, University of Strathclyde, Glasgow, UK; ${ }^{3}$ Crosshouse Hospital, Kilmarnock, UK; ${ }^{4}$ Victoria Hospital, Kirkcaldy, UK; ${ }^{5}$ Stirling Royal Infirmary, Stirling, UK; ${ }^{6}$ West of Scotland Specialist Virology Centre, Glasgow, UK; ${ }^{7}$ Royal Infirmary Edinburgh, Edinburgh, UK; ${ }^{8}$ Leicester Royal Infirmary, Leicester, UK; ${ }^{9}$ Ninewells Hospital and medical school, Dundee, UK; ${ }^{10}$ Monklands Hospital, Airdrie, UK; ${ }^{11}$ Gartnavel General Hospital, Glasgow, UK; ${ }^{12}$ Glasgow Royal Infirmary, Glasgow, UK; ${ }^{13}$ Southern General Hospital, Glasgow, UK
\end{abstract}

Introduction It is not clear what proportion of HCV (hepatitis C virus) patients attain a sustained viral response (SVR) when treated with pegylated interferon and ribavirin combination therapy outside randomised clinical trials (RCTs). Secondly, pre-treatment factors available in routine clinical settings that are predictive of SVR (the optimal treatment outcome) are not known.

Methods HCV clinical databases from nine Scottish treatment clinics were used to derive a retrospective cohort of 934 patients initiated on HCV treatment during 2000-2007.

Results In our cohort, 39\% $(123 / 315$, 95\% CI $34 \%$ to $45 \%)$ of genotype (GT) 1, and 70\% (414/594, 95\% CI $66 \%$ to $73 \%$ ) of genotype $2 / 3$ (GT2/3) patients achieved a SVR; this compares with pooled estimates of $47 \%$ for GT1 ( $95 \%$ CI $41 \%$ to $52 \%$ ), and $80 \%$ for GT2/3 (95\% CI 75\% to 85\%) patients from RCTs. Pre-treatment factors significantly associated with SVR were: gamma glutamyl transferase (GGT) $\geq 55 \mathrm{IU} / 1$ (adjusted OR: $0.46,95 \%$ CI 0.33 to $0.65)$, platelet count $\geq 150 \times 10^{9} / 1(1.92,95 \%$ CI 1.26 to 2.93$)$, ALT quotient $\geq 2.5$ (for those GT1 infected: $2.66,95 \%$ CI 1.46 to 4.84 ), GT2/3 (for those with ALT quotient <2.5: 4.05, 95\% CI 2.82 to 5.80; and for those with ALT quotient $\geq 2.5$ : $1.91,95 \%$ CI 1.01 to 3.61 ), age (per ten year increase) $(0.84,95 \%$ CI 0.72 to 0.99$)$, ever HBV infection $(0.67,95 \% \mathrm{CI} 0.45$ to 0.98$)$, and male gender $(0.70,95 \% \mathrm{CI}$ 0.50 to 0.98$)$.

Conclusions The principal conclusions are twofold: (1) the proportion of patients attaining a SVR in Scottish routine practice is marginally lower than in RCTs, and (2) in addition to genotype,
GGT (in all patients) and ALT (in GT1 patients only) emerge as valuable predictors of an SVR in the routine clinical setting.

\section{P2-123 EVALUATION OF RISK FACTOR AND PROTECTION FOR CHRONIC NON COMMUNICABLE DISEASES MONITORING SYSTEM BY PHONE SURVEY: VIGITEL, BRAZIL 2006 TO 2008}

doi:10.1136/jech.2011.142976i.58

${ }^{1} \mathrm{~B}$ Iser, ${ }^{*}{ }^{2} \mathrm{E}$ Macário, ${ }^{1} \mathrm{~J}$ Sobel, ${ }^{1} \mathrm{~L}$ Moura, ${ }^{1} \mathrm{D}$ Malta. ${ }^{1}$ National Coordination of Injury and Non-Communicable Disease Surveillance, Department of Health Analysis, Secretariat of Health Surveillance (SVS), Ministry of Health (MoH), Brasilia, Distrito Federal, Brazil; ${ }^{2}$ Field Epidemiology Training Program, Ministry of Health, Brasilia, Distrito Federal , Brazil; ${ }^{3}$ Center for Global Health, CDC, Altlanta, Georgia, USA

Vigitel is a system that monitors risk factors by means of continuous telephone interviews on samples of adults living in households with landline telephones in the Brazilian capital. To evaluate the system from 2006 to 2008, we used the Updated Guidelines for Evaluating Public Health Surveillance Systems from CDC, semistructured questionnaires for interviews with key-informants and comparisons to other surveys, such as the BRFSS.

Results The Vigitel operation has seven steps: sample selection, eligible households identification, individual selection, interview, check, closure, data management. The number of questions ranged from 78 to 92 . Among state coordinators, $96 \%$ demonstrated good knowledge of objectives and $86 \%$ of outcomes and among interviewers, $54 \%$ to $36 \%$, respectively, indicating acceptability. Lack of operation process documentation proved stability. Completeness of variables was greater than $90 \%$ and response rate higher than $70 \%$. Prevalence of smoking, high blood pressure and obesity were similar to other surveys, indicating the sensitivity to capture these factors. Changes in workers, in the questionnaire and the software didn't affect the operation. Time between final data collection and data availability was 3 months. Telephone company coverage of $80 \%$ probability sampling and data weighting make it representative. The system allows use of indicators in planning of interventions and policy development.

Conclusions The system demonstrated simplicity, acceptability, stability, and good data quality. It was flexible, opportune, representative and useful in monitoring risk factors in population. Improvement in dissemination of results, allowing local workers to perform data analysis and document system operation is necessary for to improve the system.

\section{P2-124 LOWER LIPOPROTEIN(A) LEVELS CAUSE CEREBRAL HAEMORRHAGE: THE JICHI MEDICAL SCHOOL COHORT STUDY}

doi:10.1136/jech.2011.142976i.59

${ }^{1} \mathrm{~S}$ Ishikawa, ${ }^{2} \mathrm{~K}$ Kayaba, ${ }^{1} \mathrm{~T}$ Gotoh, ${ }^{1} \mathrm{Y}$ Nakamura, ${ }^{1} \mathrm{E}$ Kajii. ${ }^{1}$ Jichi Medical University, Tochigi, Japan; ${ }^{2}$ Saitama Prefectural University, Saitama, Japan

Introduction Lipoprotein(a) ( $\operatorname{Lp}(\mathrm{a}))$ plays an important role in atherosclerosis. Some observational studies report $\mathrm{Lp}(\mathrm{a})$ as positively associated with myocardial infarction, but the relationship between $\mathrm{Lp}(\mathrm{a})$ and stroke is unclear. We examined the relationship between $\mathrm{Lp}(\mathrm{a})$ and the incidence of stroke in the general population.

Methods A multi-center population-based cohort study was conducted. A total of 10444 men and women were eligible. Data were obtained from April 1992 to July 1995 in 12 rural districts in Japan. Subjects were divided into tertiles of $L p(a)$ levels. We analysed the risks of all stroke and of stroke subtypes in each sex using Cox's proportional hazard models. 